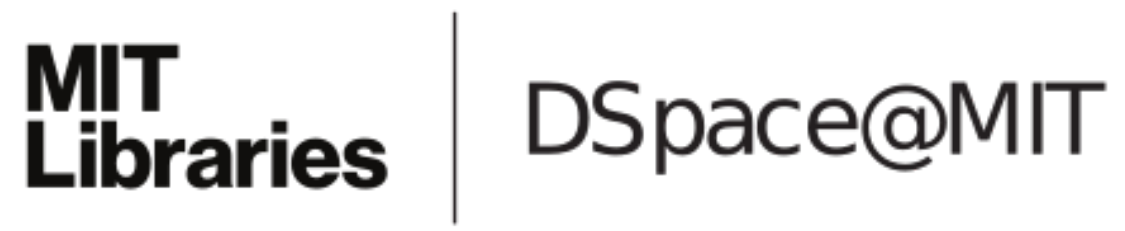

\author{
MIT Open Access Articles
}

On the Acid-Base Mechanism for

Ruthenium Water Oxidation Catalysts

The MIT Faculty has made this article openly available. Please share how this access benefits you. Your story matters.

Citation: Wang, Lee-Ping, Qin Wu, and Troy Van Voorhis. “Acid-Base Mechanism for Ruthenium Water Oxidation Catalysts." Inorganic Chemistry 49.10 (2010): 4543-4553.

As Published: http://dx.doi.org/10.1021/ic100075k

Publisher: American Chemical Society

Persistent URL: http://hdl.handle.net/1721.1/69558

Version: Author's final manuscript: final author's manuscript post peer review, without publisher's formatting or copy editing

Terms of Use: Article is made available in accordance with the publisher's policy and may be subject to US copyright law. Please refer to the publisher's site for terms of use. 


\title{
On the Acid-Base Mechanism for Ruthenium Water Oxidation Catalysts
}

\author{
Lee-Ping Wang,${ }^{\dagger}$ Qin Wu,$*$ and Troy Van Voorhis $*, \dagger$ \\ Department of Chemistry, Massachusetts Institute of Technology, 77 Massachusetts Ave. \\ Cambridge, MA 02139, and Center for Functional Nanomaterials, Brookhaven National \\ Laboratory, Upton, NY 11973. \\ E-mail: tvan@mit.edu
}

\begin{abstract}
We present a detailed theoretical study of the pathway for water oxidation in synthetic ruthenium-based catalysts. As a first step, we consider a recently discovered single center catalyst, where experimental observations suggest a purely single-center mechanism. We find low activation energies $(<5 \mathrm{kcal} / \mathrm{mol})$ for each rearrangement in the catalytic cycle. In the crucial step of $\mathrm{O}-\mathrm{O}$ bond formation, a solvent water acts as a Lewis base and attacks a highly oxidized $\mathrm{Ru}^{\mathrm{V}}=\mathrm{O}$. Armed with the structures and energetics of the single-center catalyst, we proceed to consider a representative $\mathrm{Ru}$-dimer which was designed to form $\mathrm{O}_{2}$ via coupling between the two centers. We discover a mechanism that proceeds in analogous fashion to the monomer case, with all the most significant steps occurring at a single catalytic center within the dimer. This acid-base mechanism suggests a new set of strategies for the rational design of multicenter catalysts: rather than coordinating the relative orientations of the subunits, one can focus on coordinating solvation-shell water molecules or tuning redox potentials.
\end{abstract}

${ }^{*}$ To whom correspondence should be addressed

${ }^{\dagger}$ Massachusetts Institute of Technology

${ }^{\ddagger}$ Brookhaven National Laboratory 


\section{Introduction}

The sunlight-driven splitting of water into hydrogen and oxygen is a promising long-term source of clean energy with the potential to mitigate the modern crises of fossil fuel dependence and global warming. ${ }^{1}$ Conceptually, this process may be accomplished by a photoelectrochemical cell in which a photovoltaic converts energy from sunlight into an electric current, which is used to drive the electrolysis of water.

$$
\begin{array}{ll}
2 \mathrm{H}^{+}+2 \mathrm{e}^{-} \longrightarrow \mathrm{H}_{2} & \mathrm{E}^{\circ}=0.00 \mathrm{~V} \text { vs. NHE } \\
2 \mathrm{H}_{2} \mathrm{O} \longrightarrow 2 \mathrm{H}^{+}+2 \mathrm{e}^{-}+\mathrm{O}_{2} & \mathrm{E}^{\circ}=1.23 \mathrm{~V} \text { vs. NHE }
\end{array}
$$

Within this picture, the water oxidation half reaction is especially challenging. The overall reaction is a four-electron oxidation, coupled to the transfer of four protons and the formation of an $\mathrm{O}-\mathrm{O}$ bond. The complexity of this reaction is illustrated by the prohibitive overpotentials associated with performing this reaction via any of several stepwise fashions: ${ }^{2}$

$$
\begin{array}{ll}
2 \mathrm{H}_{2} \mathrm{O} \longrightarrow 3 \mathrm{H}^{+}+3 \mathrm{e}^{-}+\mathrm{HO}_{2}^{\circ} & \mathrm{E}^{\circ}=1.66 \mathrm{~V} \text { vs. NHE } \\
2 \mathrm{H}_{2} \mathrm{O} \longrightarrow 2 \mathrm{H}^{+}+2 \mathrm{e}^{-}+\mathrm{H}_{2} \mathrm{O}_{2} & \mathrm{E}^{\circ}=1.76 \mathrm{~V} \text { vs. NHE } \\
\mathrm{H}_{2} \mathrm{O} \longrightarrow \mathrm{H}^{+}+\mathrm{e}^{-}+\mathrm{OH}^{\cdot} & \mathrm{E}^{\circ}=2.72 \mathrm{~V} \text { vs. NHE }
\end{array}
$$

Thus, the optimal pathway is likely to be highly concerted, and special catalysts are needed to perform this reaction at potentials accessible using photovoltaics that capture visible light.

Nature catalyzes water oxidation using a $\mathrm{Mn}_{4}$ cluster embedded within the oxygen-evolving complex (OEC) of photosystem II. ${ }^{3,4}$ This remarkable metalloprotein system oxidizes water at efficiencies and rates that far exceed those of any synthetic catalyst. ${ }^{5}$ There have been many efforts to resolve the structure of the OEC in plants using X-ray studies, ${ }^{6-9}$ as well as experimental ${ }^{5,10-21}$ and computational ${ }^{22-24}$ efforts to understand the mechanism of water splitting within the OEC. The essential steps of the water oxidation mechanism can also be studied rigorously and compre- 
hensively by focusing on much simpler synthetic systems, which do not have the extensive protein scaffolding that often complicates efforts to understand the natural system.

Toward this end, a number of synthetic catalysts for water oxidation have been synthesized and characterized, ranging from single-center transition metal complexes, ${ }^{25-27}$ dimers, ${ }^{28-31}$ and four-center clusters ${ }^{32,33}$ to amorphous materials ${ }^{34}$ and periodic metal-oxide systems. ${ }^{35,36}$ Wellcharacterized families of catalysts, e.g. the two-center ruthenium catalysts based upon the famous blue dimer, ${ }^{28}$ have demonstrated that catalyst performance can depend on chemical and structural variation; however, a method for systematic catalyst optimization remains elusive, highlighting the need for mechanistic understanding. Recently, theoretical studies using density functional theory $(\mathrm{DFT})^{2,27,37-44}$ have been helpful in the effort to understand the water oxidation mechanism by providing highly detailed geometrical and energetic data at the atomistic level.
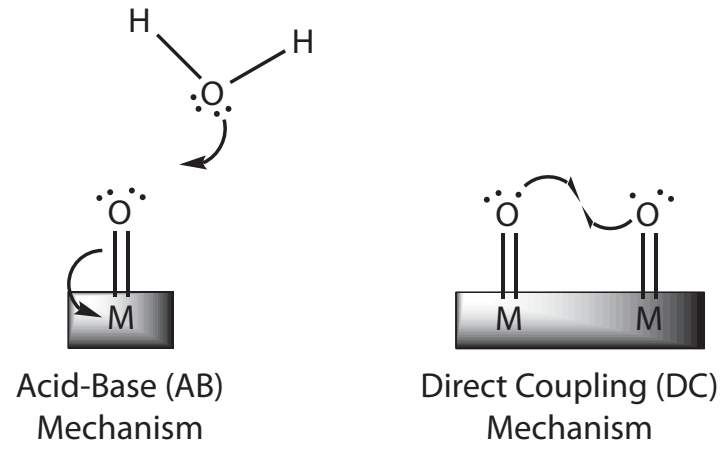

Figure 1: Schematic representations of acid-base and direct coupling pictures.

There are currently two dominant pictures for the water oxidation mechanism, ${ }^{45,46}$ known as acid-base (AB) and direct coupling (DC) (Figure 1). In the AB picture, an oxygen nucleophile (e.g. water or hydroxide) attacks a metal-bound, electrophilic oxo group. From an orbital perspective, an orbital of $\sigma$ character (HOMO) approaches the $\mathrm{M}-\mathrm{O} \pi^{*}$ orbital (LUMO). The combination leads to the formation of an $\mathrm{O}-\mathrm{O} \sigma$ bond while breaking one of the $\mathrm{M}-\mathrm{O} \pi$ bonds, representing a formal $2 \mathrm{e}^{-}$reduction of the metal center. The $\mathrm{AB}$ picture is thought to describe the $\mathrm{O}-\mathrm{O}$ bond forming chemistry in the oxygen-evolving complex of photosystem II. ${ }^{47}$

In the $\mathrm{DC}$ picture, $\mathrm{O}-\mathrm{O}$ bonding occurs between two metal-bound radicaloid oxo groups. The 
$\mathrm{O}-\mathrm{O}$ bonding orbital arises from combining two singly occupied orbitals of $\mathrm{M}-\mathrm{O} \pi^{*}$ character. While there is no biological precedent for the DC picture, it has been widely implicated in the design of two-center water oxidation catalysts, many of which use cofacial or conformationally locked geometries to encourage direct coupling. ${ }^{31,46}$ Muckerman and coworkers ${ }^{2}$ have performed DFT studies on a two-center catalyst developed in the Tanaka $\mathrm{lab}^{29}$ and found stable intermediates containing direct $\mathrm{O}-\mathrm{O}$ coupling. Muckerman's study contains many interesting insights into the proposed catalyst intermediates, but no energetics were provided to assess the viability of the overall cycle.

Recently, the $\mathrm{AB}$ picture has received increasing attention as a possible operative mechanism in synthetic water-splitting catalysts. ${ }^{43,45}$ The $\mathrm{AB}$ picture was suggested early on by Hurst as a possible pathway for the blue dimer ${ }^{48}$ and this has been supported recently by experimental studies which suggest nucleophilic attack of water as a key step. ${ }^{37,49}$ More recently, Yang and Baik have proposed that the $\mathrm{AB}$ picture is operative for the two-center Ru-Hbpp water-oxidation catalyst developed in the Llobet $l^{3} b^{30}$ based on a detailed computational investigation of both pathways, but the results have been somewhat controversial as more recent isotopic labeling experiments ${ }^{46}$ and calculations ${ }^{44}$ appear to favor the DC picture instead. In addition, the recent emergence of single-center catalysts in the Thummel, Bernhard, Sakai, and Meyer labs ${ }^{25-27,50-52}$ suggest that the entire catalytic cycle can be accomplished at a single metal center. Recent experimental studies of single-center catalysts on oxide surfaces ${ }^{53}$ and in multi-component light-driven water oxidation systems ${ }^{54}$ provide further support for the viability of the $\mathrm{AB}$ picture, and work has begun on optimizing these catalysts by adjusting the electronic parameters of the ligands. ${ }^{55}$

The purpose of this paper is to assess the viability of the $\mathrm{AB}$ picture as a mechanism for water oxidation. We first conduct a thorough mechanistic investigation of a recently-published single-center catalyst; ${ }^{25}$ our findings strongly indicate that the catalyst operates via the $\mathrm{AB}$ picture, providing verification for Concepción and Meyer's original proposal ${ }^{25,51}$ with some slight modifications. We then present a water oxidation cycle for a two-center catalyst, ${ }^{45}$ which had been designed in accordance with the DC picture. We find that the water oxidation mechanism proceeds 
via an $\mathrm{AB}$ picture highly similar to that of the single-center catalyst.

We conclude with several proposals and suggestions for both the theoretical and experimental wings of the catalyst development community. From a theoretical standpoint, our methodology demonstrates the importance of using explicit solvent when investigating reaction kinetics and barriers, a consideration that has often been overlooked in previous computational work. In terms of catalyst design, our conclusions strengthen the $\mathrm{AB}$ mechanistic hypothesis and suggest that catalysts optimized for the $\mathrm{AB}$ pathway should be a fruitful avenue of study.

\section{Computational Details}

\section{General}

The calculations in this paper can be roughly divided into two categories; the determination of energies for intermediates, and the investigation of reaction pathways. The determination of energetics required single-point energy calculations in the solvent phase, geometry optimizations, and frequency calculations. Reaction pathway investigations involved constrained geometry optimizations, transition state searches, and molecular mechanics (MM) simulations for thermodynamic sampling.

All DFT calculations were carried out using the B3LYP hybrid exchange-correlation functional. ${ }^{56}$ Geometry optimizations, frequency calculations, and transition state searches were performed in the gas phase using the $6-31 \mathrm{G}^{*}$ basis set ${ }^{57} \mathrm{Ru}$ atoms were represented using the Los Alamos LANL2DZ effective core potential. ${ }^{58}$ In all cases, the crystal-field-derived spin states were computationally verified to be the lowest-energy configurations; all states were modeled using the unrestricted-spin formalism and a broken symmetry guess. We employed constrained $\mathrm{DFT}^{59}$ to obtain the symmetric mixed-valence electronic states in the two-center catalyst, where conventional DFT suffers systematic errors due to electron self-interaction. ${ }^{60}$ Single-point energies in the solvent phase were computed at the gas-phase optimized geometries using the expanded TZVP 61 basis and the Stuttgart/Dresden $\mathrm{ECP}^{62}$ for $\mathrm{Ru}$ atoms. The solvating effect of water was represented 
using the C-PCM polarizable continuum model. ${ }^{63}$ Solvated energies were calculated using GAUSSIAN $03^{64}$ and all other electronic structure calculations were performed in Q-Chem 3.1. ${ }^{65}$ The MM simulations, described below, were performed in GROMACS. ${ }^{66}$

\section{Redox Potentials}

We calculated redox potentials for oxidative couples in the catalytic cycle using the polarizable continuum model for solvent effects; ${ }^{67,68}$ our approach is also highly similar to the method proposed by Nørskov et al. ${ }^{69}$ for determining reaction free energies in solid-state catalysts. The redox potentials are related to the standard reduction free energy in solution by

$$
-F E^{\circ}=\Delta G_{(\mathrm{sol})}^{\mathrm{oEA}}
$$

where $\Delta \mathrm{G}_{(\mathrm{sol})}^{\circ \mathrm{EA}}$ is the free energy change associated with reduction in a solvent environment at standard conditions and $\mathrm{F}$ is the Faraday constant. $\Delta \mathrm{G}_{(\mathrm{sol})}^{\mathrm{oEA}}$ is the difference between several energy components computed for the reduced and oxidized species.

$$
\begin{gathered}
\Delta G_{(\mathrm{sol})}^{\mathrm{oEA}}=\Delta G_{(\mathrm{g})}^{\mathrm{oEA}}+\Delta \Delta G_{\mathrm{solv}} \\
\Delta G_{(\mathrm{g})}^{\mathrm{oEA}}=\Delta E_{\mathrm{SCF}}+\Delta H^{\mathrm{T}}-T \Delta S_{(\mathrm{g})}
\end{gathered}
$$

$E_{\mathrm{SCF}}$ is the gas-phase electronic energy, $H^{\mathrm{T}}$ is the gas-phase enthalpy correction (including the vibrational zero-point energy), $-T S$ is the entropic contribution to the Gibbs free energy, and $\Delta G_{\text {solv }}$ is the free energy of solvation.

A large portion of oxidation events are characterized by proton-coupled electron transfer (PCET), where electron transfer (ET) is accompanied by proton transfer (PT) to the solvent. Thus, there are many redox potential calculations for which we must include the standard free energy of a proton in solution, $G_{(\mathrm{aq})}^{\mathrm{OH}+}$. (Ref. 70)

$$
G_{(\mathrm{aq})}^{\mathrm{OH}+}=G_{(\mathrm{gas})}^{\mathrm{oH}+}+\Delta G_{\mathrm{solv}}^{\mathrm{H}+}
$$


We adopt a widely accepted value for the free energy of solvation of a proton, $\Delta G_{\mathrm{solv}}^{\mathrm{H}+}=-265.9$ $\mathrm{kcal} / \mathrm{mol} .{ }^{71}$ The gas-phase Gibbs free energy is a small correction, given by $G_{(\text {gas })}^{\circ \mathrm{H}+}=\frac{3}{2} k T+P V-$ $T S=-6.3 \mathrm{kcal} / \mathrm{mol}$, and yields the final value of $G_{(\mathrm{aq})}^{\mathrm{oH}+}=-11.803 \mathrm{eV}$.

Thus far, $\mathrm{E}^{\circ}$ has been referenced to vacuum. We obtain potentials referenced to $\mathrm{NHE}\left(\mathrm{E}_{a b s}=\right.$ $-4.24 \mathrm{~V}^{72}$ ) via:

$$
E^{\circ}=-\frac{1}{F} \times\left(\Delta G_{(\mathrm{g})}^{\mathrm{oEA}}+\Delta G_{\mathrm{solv}}-n_{\mathrm{H}_{+}} \times G_{(\mathrm{aq})}^{\mathrm{oH}+}\right)-4.24 V
$$

The measured redox potential $E_{\frac{1}{2}}$ at experimental $\mathrm{pH}$ conditions is related to standard conditions ( $\mathrm{pH}$ ) using the Nernst equation:

$$
E_{\frac{1}{2}}=E^{\circ}-\frac{R T}{F} \ln (10) \times \frac{\mathrm{n}_{\mathrm{H}_{+}}}{\mathrm{n}_{\mathrm{e}}} \times \mathrm{pH}
$$

where $n_{e}$ and $n_{\mathrm{H}_{+}}$are the number of electrons and protons involved in the redox reaction. At experimental conditions (the experiments using $\mathrm{Ce}^{\mathrm{IV}}$ are performed at $\mathrm{pH} 1$ ), $59 \mathrm{mV}$ is subtracted from the standard potential for each proton transferred.

Using this method, we first calculated the redox potentials for a set of well-characterized organic molecules and metallocenes; ${ }^{68}$ our method reproduced the experimental values well, with a mean absolute error (MAE) of $0.15 \mathrm{~V}$ (Figure S1). Following this, we computed redox potentials for a large number of ruthenium transition metal complexes with experimentally determined redox potentials. ${ }^{73,74}$ We found a systematic deviation between calculated and experimental redox potentials; our model underestimated small values of $E^{\circ}$ and overestimated large values. This suggests that the redox potentials are largely governed by explicit solvent effects, coordinating anions, and/or electronic effects ${ }^{73}$ that are beyond the descriptive capability of our model. However, a linear fit (Figure S2) demonstrates strong correlation between theory and experiment. Thus, the final potentials are given by $E_{\text {calc }}^{\circ}=a E_{\text {raw }}^{\circ}+b$ where $E_{\text {raw }}^{\circ}$ is the raw calculated potential, and $a=0.528$ and $b=0.623$ are fitting parameters; redox potentials for the catalyst itself are not included in the fit. The MAE of our predictions using the linear regression is $0.11 \mathrm{~V}$, and should be considered as the typical uncertainty in subsequent values of $E_{\text {calc }}^{\circ}$ in this report. 


\section{Reaction Path Investigations}

A key concern surrounding the proposed mechanism is whether it makes predictions in agreement with the experimentally observed intermediates and measured kinetics. We address this question by investigating the reactivity of catalyst intermediates before and after oxidation events. Many of these reactions involve solvent water molecules as reactants or proton acceptors; to address the role of solvent, we developed a procedure to study catalytic steps that incorporates explicit, thermally sampled solvent configurations.

We first performed exploratory sampling of the solvent configuration space, in which the catalyst interacts with solvent through a simple MM force field using OPLS-AA ${ }^{75}$ Lennard-Jones interactions and Mulliken partial charges. The geometry of the catalyst was fixed at the gas-phase optimized configuration for the duration of the simulation. Numerous snapshots of the catalyst and its solvation environment $\left(\approx 800\right.$ water molecules, modeled with the SPC/E $\mathrm{E}^{76}$ force field) were sampled from an $\mathrm{NPT}^{77,78}$ equilibrated simulation at fixed time intervals. From these snapshots, the catalyst is extracted along with several nearby water molecules (the water nearest the oxo group, and its three nearest neighbors) for DFT calculations. The sampled configurations were fully relaxed to the quantum energy surface using a geometry optimization. Oxidation events were simulated by removing an electron from the system at the relaxed configuration. Following oxidation, the geometries were re-optimized, and the optimized configurations and energies were analyzed to determine whether spontaneous reactions occurred. Reaction barriers for non-spontaneous steps were determined using a transition state search.

\section{Single-Center Catalyst}

We begin with the water oxidation mechanism of the single-center catalyst, $\left[\mathrm{Ru}^{\mathrm{II}}(\mathrm{tpy})(\mathrm{bpm})\left(\mathrm{OH}_{2}\right)\right]^{2+}$. (Ref. 25) The coordination environment of the central $\mathrm{Ru}$ atom is pseudo-octahedral, and catalysis occurs at the water-bound site. Kinetic studies in Ref. 25 have shown that the rate of water oxidation is first-order in the catalyst concentration, indicating that no more than one metal center 


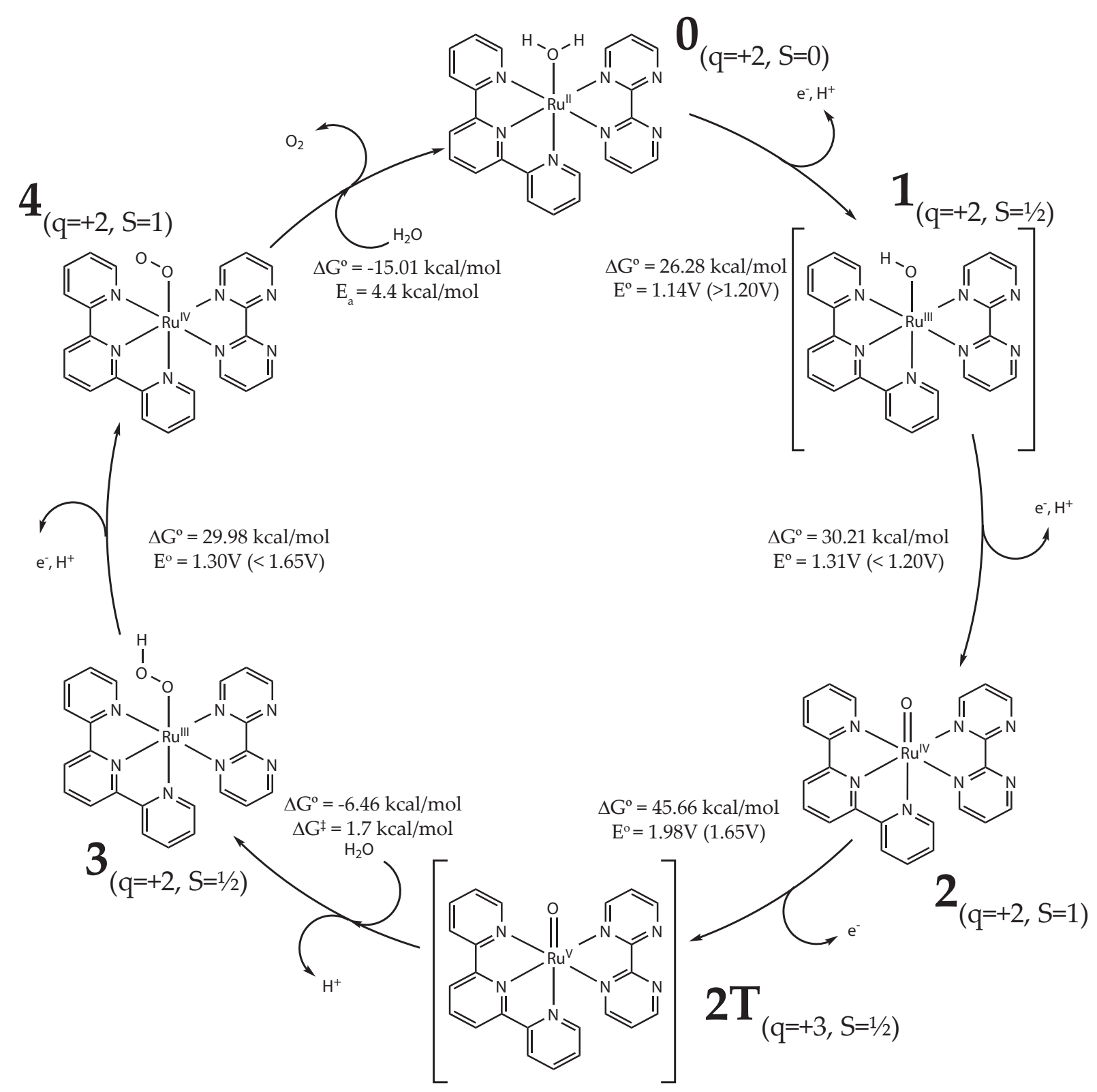

Figure 2: Complete catalytic cycle for the single-center water oxidation catalyst. Lowest-energy spin states are denoted in subscripts. Bracketed species are not experimentally observed. The $\mathrm{Ru}^{\mathrm{V}}$ species is sufficiently high in energy and unstable that we denote it using " $2 \mathrm{~T}$ ", where "T" stands for "transient". Experimental values for redox potentials are reported in parentheses. For brevity, numerical labels are used to denote the various intermediates throughout the paper.

is involved in the rate-determining step, and perhaps the entire catalytic cycle. Concepción and Meyer have proposed that the water oxidation mechanism for this catalyst proceeds via the $A B$ picture, in which a water molecule attacks an electrophilic oxo group bound to the highly oxi- 
dized $\mathrm{Ru}^{\mathrm{V}}$. The purpose of this theoretical study is to explore the water oxidation mechanism and the intermediates involved. Here, we present a complete picture of the catalytic cycle, including calculations of all reactants, products, intermediates, energetics, and reaction barriers.

\section{Energetics and Redox Potentials}

Four oxidation events are required for the production of a single oxygen molecule. The various intermediates in the catalytic cycle are labeled in Figure 2, beginning with the aquo complex $\mathrm{Ru}^{\mathrm{II}}\left(\mathrm{OH}_{2}\right)$, labeled as 0. Experimental measurements and their interpretation are as follows. A two-electron wave is observed at $1.20 \mathrm{~V}$ vs. NHE, taking the aquo complex $\mathbf{0}$ directly to the oxo species $\mathrm{Ru}^{\mathrm{IV}}(\mathrm{O})(\mathbf{2})$. The hydroxo species $\mathbf{1}$ is not experimentally observed, indicating that it disproportionates to $\mathbf{0}$ and $\mathbf{2}$; thus the redox potentials of the $\mathrm{Ru}{ }^{\mathrm{II}} / \mathrm{Ru}^{\mathrm{III}}$ and $\mathrm{Ru}{ }^{\mathrm{III}} / \mathrm{Ru}^{\mathrm{IV}}$ couples average out to $1.20 \mathrm{~V}$, with the former being higher. Both oxidation events are $\mathrm{pH}$-dependent PCET steps. At $1.65 \mathrm{~V}$, a $\mathrm{pH}$-independent one-electron wave appears as a prefeature of the catalytic wave, and is assigned to the oxidation of 2 to $\mathrm{Ru}^{\mathrm{V}}(\mathrm{O})(\mathbf{2 T})$. $2 \mathrm{~T}$ contains the highly oxidized $\mathrm{Ru} \mathrm{V}^{\mathrm{V}}$, which undergoes nucleophilic attack by a solvent water molecule, forming an oxygen-oxygen bond and losing a proton to create the hydroperoxo complex $\mathrm{Ru}^{\mathrm{III}}(\mathrm{OOH})(\mathbf{3})$. This complex is oxidized a fourth and final time to yield the peroxo complex $\mathrm{Ru}^{\mathrm{IV}}(\mathrm{OO})(4)$; this fourth couple has an unknown potential that is bounded from above by the catalytic wave. The peroxo complex 4 returns to the rest state $\mathbf{0}$ via displacement of the peroxo group by a solvent water molecule, releasing oxygen.

The four calculated standard redox potentials in this catalytic cycle are shown in Figure 2. For the $\mathrm{Ru}^{\mathrm{II}} / \mathrm{Ru}^{\mathrm{III}}$ redox couple $(\mathbf{0} \rightarrow \mathbf{1})$, our calculated value of $1.14 \mathrm{~V}$ is a slight underestimate compared to the experimentally reported lower bound of $1.20 \mathrm{~V}$. We calculated the potential for the $\mathrm{Ru}^{\mathrm{III}} / \mathrm{Ru}^{\mathrm{IV}}$ couple $(\mathbf{1} \rightarrow \mathbf{2})$ to be $1.31 \mathrm{~V}$, which is an overestimate, given that the experimentally reported upper bound is $1.20 \mathrm{~V}$. Unfortunately, our protocol gives the incorrect ordering of the redox potential and does not reproduce the experimentally reported disproportionation of $\mathbf{1}$. However, we note that our theoretical predictions agree with experiment to within the margins of error (110 $\mathrm{mV}$ ). 
The calculated redox potential for the $\mathrm{Ru}^{\mathrm{IV}} / \mathrm{Ru}^{\mathrm{V}}$ couple $(\mathbf{2} \rightarrow \mathbf{2 T})$ is very high at $1.98 \mathrm{~V}$ - this potential lies $330 \mathrm{mV}$ above the $1.65 \mathrm{~V}$ prefeature, which is where Concepción and Meyer observe the redox couple. This redox couple is a necessary part of the mechanism, because the experimental observation of a $\mathrm{pH}$-independent catalytic wave ${ }^{53}$ dictates that the highest redox potential must not be coupled to PT. This statistically significant discrepancy between computation and experimental observation persists through our explorations of different density functionals, basis sets, and electronic states; more comprehensive simulation techniques, such as fully explicit solvent models or the inclusion of counterions, may be essential for determining the redox potentials of these highly oxidized species. The disagreement between theory and experiment may be exacerbated by the fact that $\mathbf{2 T}$ is the only species in the entire cycle with a +3 charge. Alternatively, the oxidation of 2 at $1.65 \mathrm{~V}$ may be possible as an activated process, but reaching 2T would require crossing an additional kinetic barrier. The calculated potential for the final redox couple $(\mathbf{3} \rightarrow \mathbf{4})$ is $1.30 \mathrm{~V}$, below the experimental upper bound of $1.65 \mathrm{~V}$.

\section{Oxygen-Oxygen Bonding}

The $\mathrm{O}-\mathrm{O}$ bonding step is the primary focus of our study. This step is the most chemically interesting, because it corresponds directly to the $\mathrm{AB}$ picture where a water nucleophile attacks an electrophilic metal oxo group. In preliminary investigations, we tested a number of alternatives to the proposal in Ref. 25. We found no stable $\mathrm{O}-\mathrm{O}$ bonded structure involving $\mathrm{Ru}^{\mathrm{IV}}(\mathrm{O})$; this indicates that higher oxidation states are essential for $\mathrm{O}-\mathrm{O}$ bonding. We also found that any bimolecular $\mathrm{O}-\mathrm{O}$ bonded structure $\mathrm{Ru}^{\mathrm{IV} / \mathrm{V}}(\mathrm{O})-(\mathrm{O}) \mathrm{Ru}^{\mathrm{IV} / \mathrm{V}}$ is at least $100 \mathrm{kcal} / \mathrm{mol}$ higher in energy than the two monomers, which is likely a consequence of electrostatic repulsion between these positively charged species. Despite our likely overestimation of the repulsion (counterions were omitted from the calculation), our results largely rule out a bimolecular non-rate-determining step, which would have been difficult to detect by experimentally measuring the overall rate.

After eliminating the possibility of bimolecular direct coupling, we examined the addition of water to $\mathrm{Ru}^{\mathrm{V}}(\mathrm{O})(\mathbf{2 T} \rightarrow \mathbf{3})$. The kinetics surrounding water addition is instrumental for validating 


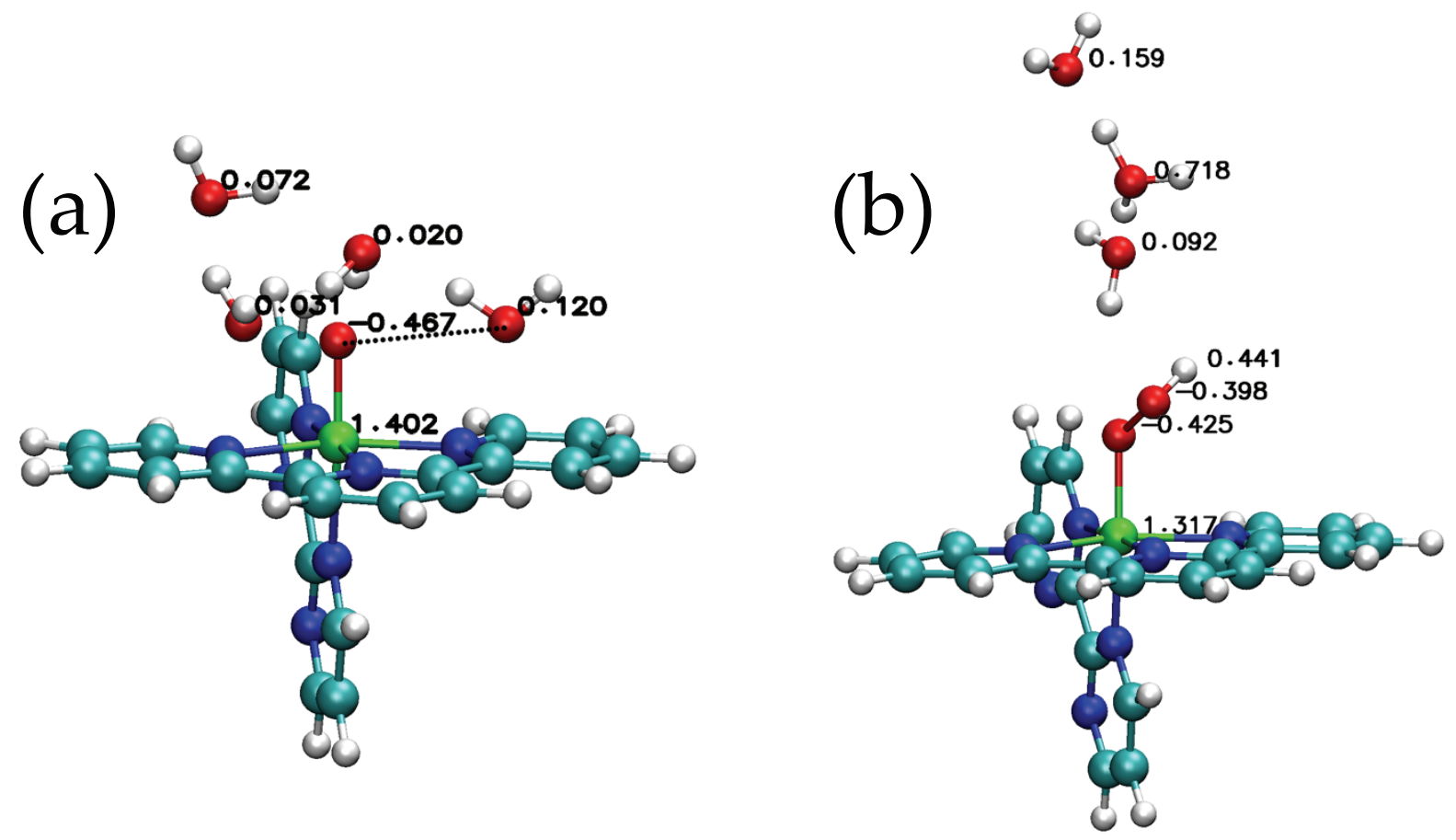

Figure 3: Starting and ending points of a geometry optimization starting at $\mathrm{Ru}^{\mathrm{V}}(\mathrm{O})$ and ending at $\mathrm{Ru}^{\mathrm{III}}(\mathrm{OOH})$. The color scheme is: $\mathrm{Ru}$ (green), $\mathrm{C}$ (teal), $\mathrm{N}$ (blue), $\mathrm{O}$ (red), $\mathrm{H}$ (white). The reacting oxygen atoms are connected by a dotted line. Selected Mulliken populations are labeled. Charges on the water hydrogen atoms are summed into the oxygen atoms.

the proposed mechanism; for example, finding a kinetic barrier to water addition would predict the observation of $\mathbf{2 T}$ in the reaction mixture, contradicting the experimental observations and bringing the proposed mechanism into question. We used explicit solvent simulations as detailed in the Computational Methods section to model this critical step.

40 configurations of $\mathbf{2}+4 \mathrm{H}_{2} \mathrm{O}$ were sampled, fully relaxed, and then oxidized. After oxidation of the system to $2 \mathbf{T}+4 \mathrm{H}_{2} \mathrm{O}$ and subsequent relaxation, we observed that 3 out of 40 configurations spontaneously underwent the reaction $2 \mathrm{~T}+4 \mathrm{H}_{2} \mathrm{O} \rightarrow \mathbf{3}+2 \mathrm{H}_{2} \mathrm{O}+\mathrm{H}_{3} \mathrm{O}^{+}$. These reactions proceeded by nucleophilic attack of a water molecule on the metal oxo group, forming an $\mathrm{O}-\mathrm{O}$ bond, coupled with PT to a neighboring water molecule. The Mulliken charge analysis clearly indicates that a unit of positive charge is transferred to the solvent after PT (Figure 3). The distribution of energies energies shows that the $3 \mathrm{O}-\mathrm{O}$ bonding configurations had initial energies within $5 \mathrm{kcal} / \mathrm{mol}$ of 
the mean, and lower final energies than the other 37 configurations by $\approx 18 \mathrm{kcal} / \mathrm{mol}$.

Our calculations confirm that the bonding step is thermodynamically favorable; solvent-phase calculations give a driving force of $\Delta G=-6.5 \mathrm{kcal} / \mathrm{mol}$ at experimental conditions. The reaction pathway of the $\mathrm{O}-\mathrm{O}$ bonding step $(\mathbf{2 T} \rightarrow \mathbf{3})$, characterized by nucleophilic attack of a water molecule followed by PT, is consistent with the AB picture for water oxidation.

We estimated the free energy of activation for $\mathbf{2} \mathbf{T} \rightarrow \mathbf{3}$ using transition state theory. Using $3 / 40$ as the reaction probability allows us to estimate the free energy of activation using $\Delta G^{\ddagger}=$ $-k T \ln \left(\mathrm{P}_{\mathrm{rxn}}\right) \approx 1.7 \mathrm{kcal} / \mathrm{mol}$. Although our sample size is small, it is clear that $2 \mathrm{~T}$ is a transient species that reacts readily with water at room temperature $(k T=0.6 \mathrm{kcal} / \mathrm{mol})$. Our calculation of a small free energy barrier may help to explain the difficulty in detecting $\mathbf{2 T}$ in experiments.

The remaining 37 out of 40 configurations relaxed to a variety of final geometries; they are listed here in order of increasing energy. In one case, $\mathrm{O}-\mathrm{O}$ bonding was not followed by PT. In another case, a solvent water molecule attacked a carbon atom in the 3 position of the tpy ligand, followed by PT to the solvent water molecules to form 3-hydroxyl-tpy. Water addition to the ligand has been previously observed in the blue dimer; ${ }^{79}$ this is reminiscent of a ligand-based water oxidation hypothesis proposed by Yamada and Hurst, ${ }^{49,80}$ but may also be an indicator of eventual catalyst degradation. 24 cases resulted in an $\mathrm{O}-\mathrm{O}$ approach distance ranging from 1.9 $\AA$ to $2.2 \AA$, with no covalent bonding. In 11 cases, the water molecules migrated far away from the oxo group and no reactivity occurred after oxidation. The variety of final states for this step is indicative of the high reactivity of the $\mathrm{Ru}^{\mathrm{V}}$ center.

We examined bond lengths and molecular orbitals through the course of $\mathrm{O}-\mathrm{O}$ bonding to verify consistency with the $\mathrm{AB}$ picture. We found that oxidation from $\mathrm{Ru}^{\mathrm{IV}}$ to $\mathrm{Ru}^{\mathrm{V}}(\mathbf{2} \rightarrow \mathbf{2 T})$ caused the $\mathrm{Ru}-\mathrm{O}$ bond to shorten from $1.78 \AA$ to $1.71 \AA$, and reduced the Mulliken spin populations on $\mathrm{Ru}$ and $\mathrm{O}$ from $1.0 / 1.0$ to $0.5 / 0.5$. This is consistent with removing an electron from a $\mathrm{Ru}-\mathrm{O} \pi^{*}$ orbital and increasing the bond order to 2.5. The subsequent nucleophilic attack of water and $\mathrm{O}-$ O bonding $(\mathbf{2 T} \rightarrow \mathbf{3})$ resulted in an $\mathrm{O}-\mathrm{O}$ bond with length $1.37 \AA$, characteristic of a bond order of 1 ; the $\mathrm{Ru}-\mathrm{O}$ bond order decreased as the bond lengthened from $1.71 \AA$ to $1.94 \AA$. Once again, 

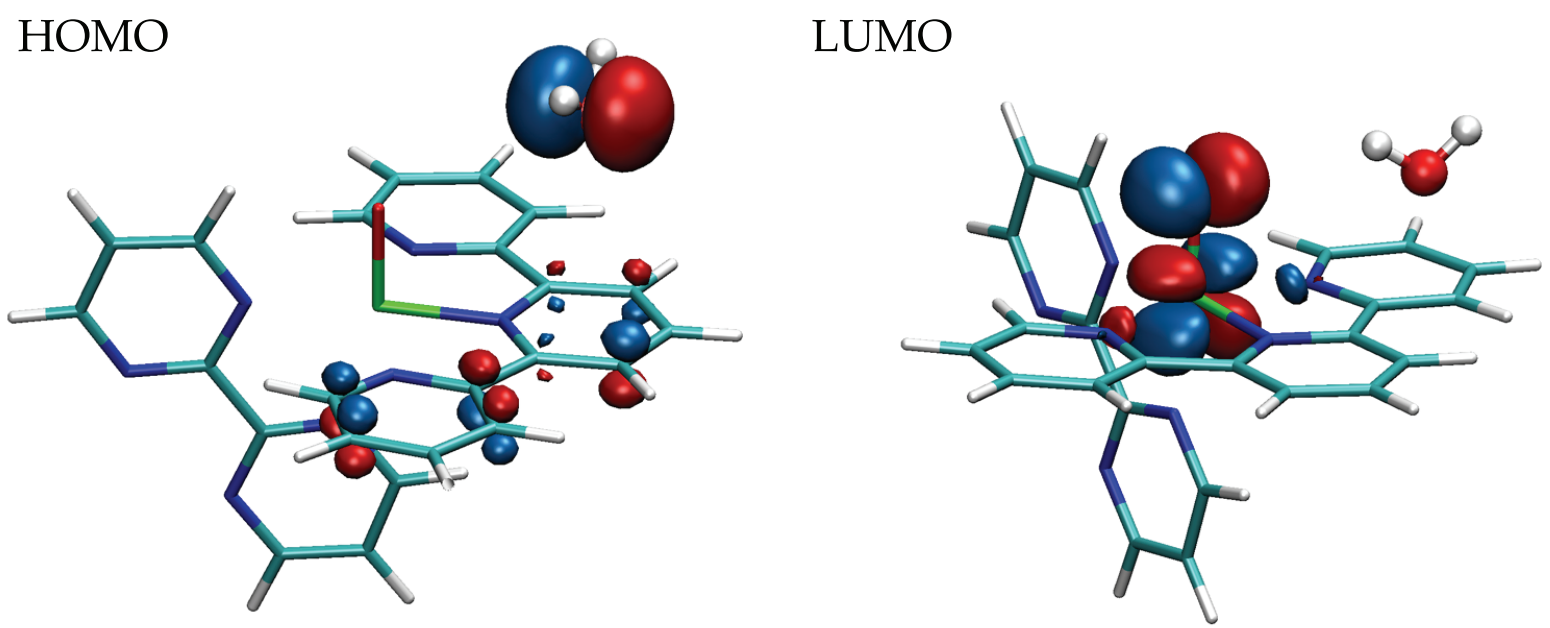

Figure 4: Isosurface plots of the HOMO and LUMO in $\mathbf{2 T}+\mathrm{H}_{2} \mathrm{O}$. These two orbitals combine to create the $\mathrm{O}-\mathrm{O} \sigma$ bond. Note the $\mathrm{Ru}-\mathrm{O}$ antibonding $\pi^{*}$ character of the LUMO; $\mathrm{O}-\mathrm{O}$ bonding simultaneously weakens the $\mathrm{Ru}-\mathrm{O}$ bond. The orientation of the $\mathrm{H}_{2} \mathrm{O}$ molecule may significantly affect $\mathrm{O}-\mathrm{O}$ bonding, due to the importance of HOMO-LUMO overlap.

this demonstrates consistency with the $A B$ picture, for the $\mathrm{O}-\mathrm{O} \sigma$ bonding orbital is predicted to have $\mathrm{Ru}-\mathrm{O}$ antibonding $\pi^{*}$ character (Figure 4). Figure 4 shows that the water $1 \mathrm{~b}_{1}$ molecular orbital must be oriented towards the $\mathrm{Ru}-\mathrm{O}$ axis for bonding to occur; it may be possible to design catalysts which coordinate nearby water molecules to facilitate this process.

\section{Dioxygen Displacement}

The $\mathrm{O}-\mathrm{O}$ bonding step takes the catalytic cycle to the hydroperoxo complex $\mathrm{Ru}^{\mathrm{III}}(\mathrm{OOH})(\mathbf{3})$. From here, we have a fourth and final proton-coupled redox event that takes us to the peroxo complex $\mathrm{Ru}^{\mathrm{IV}}(\mathrm{OO})(\mathbf{3} \rightarrow \mathbf{4})$. We performed an investigation of this reaction path using the explicit solvent method. We found that for all 40 sampled configurations, the oxidized $\mathrm{Ru}^{\mathrm{IV}}(\mathrm{OOH}) \mathrm{com}-$ plex deprotonated immediately to yield 4 . The $\mathrm{Ru}-\mathrm{O}$ bond lengthens even more to $2.13 \AA$ while the $\mathrm{O}-\mathrm{O}$ bond shortens to $1.23 \AA$; this indicates an increase in $\mathrm{O}-\mathrm{O}$ bond order and an accompanying decrease in the $\mathrm{Ru}-\mathrm{O}$ bond order, in accordance with the $\mathrm{AB}$ picture. Unlike the $\mathrm{O}-\mathrm{O}$ bonding step, the solvent water molecules were predisposed toward PT, due to hydrogen bonding 
with the hydroperoxo group. Our results show that the fourth oxidation very likely follows a PCET pathway, similar to the first two oxidations. The absence of a kinetic barrier for this step predicts that $\mathbf{3}$ is not an observed intermediate, in agreement with experimental observations.

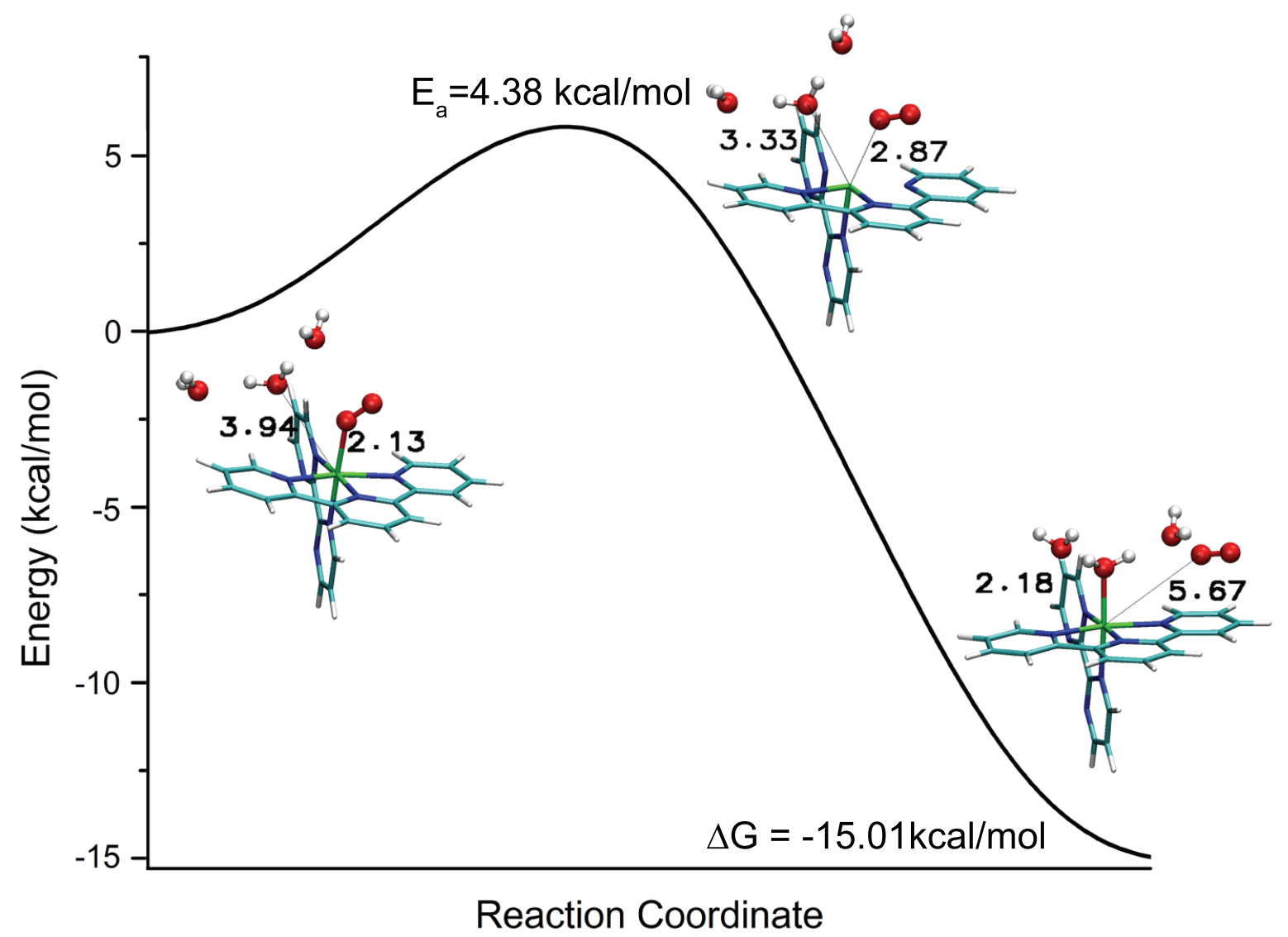

Figure 5: Reaction diagram for oxygen displacement comparing the geometries and energetics of the starting, ending, and transition state configurations. 3-D plots of the system are shown at the initial, final, and transition states. Key distance measurements $(\mathrm{H} 2 \mathrm{O}-\mathrm{Ru}$ and $\mathrm{OO}-\mathrm{Ru})$ are indicated.

Finally, we examined the reaction barrier for the oxygen displacement step $\mathbf{4}+\mathrm{H}_{2} \mathrm{O} \rightarrow \mathbf{0}+\mathrm{O}_{2}$. Energy minima were found for the endpoints of the oxygen displacement reaction, $4+3 \mathrm{H}_{2} \mathrm{O} \rightarrow \mathbf{0}$ $+\mathrm{O}_{2}+2 \mathrm{H}_{2} \mathrm{O}$. We found the energy minimum for $\mathbf{4}$ to be a triplet six-coordinate structure, rather than the seven-coordinate singlet proposed in Refs. 25 and 51. Solvent-phase energy calculations of the endpoints give a significant forward driving force of $\Delta G=-15.0 \mathrm{kcal} / \mathrm{mol}$. The geometries 
of the endpoints are shown in Figure 5.

The transition state for $\mathbf{4} \rightarrow \mathbf{0}$ was found with a small barrier of $4.4 \mathrm{kcal} / \mathrm{mol}$ (Figure 5 ). In this geometry, the $\mathrm{Ru}-\mathrm{OO}$ distance is $2.87 \AA$, and the $\mathrm{Ru}-\mathrm{OH}_{2}$ distance is $3.33 \AA$. The $\mathrm{OO}-\mathrm{Ru}-$ $\mathrm{OH}_{2}$ angle is 52.2 degrees, and it is nearly exactly bisected by the vertical axis running through the octahedral coordination site. We can infer from this investigation that the oxygen displacement step, the only step that is not triggered by oxidation, has a significant downhill driving force and a small enough activation barrier that it proceeds under experimental conditions at a limited rate. The presence of an activation barrier is in agreement with the observed appearance of the intermediate 4 in the reaction mixture; Concepción and Meyer report that this is the rate-determining step. ${ }^{51}$ Following replacement of dioxygen by water, the catalyst returns to the rest state $\mathbf{0}$ and the catalytic cycle is completed.

\section{Two-Center Catalyst}

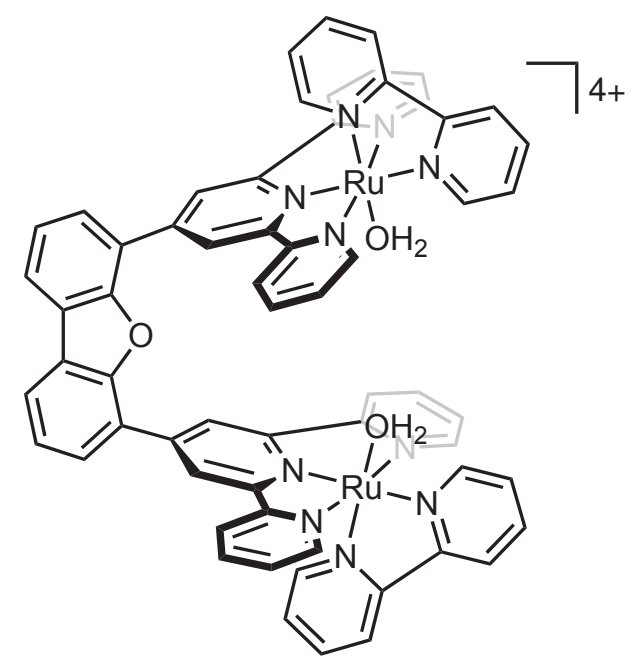

Figure 6: Dibenzofuran (DBF) bridged two-center ruthenium catalyst.

Following our investigation of the water oxidation mechanism in the single-center catalyst, we turn our attention to a two-center catalyst. We have investigated the reaction mechanism of the dibenzofuran $(\mathrm{DBF})$ bridged two-center $\mathrm{Ru}^{\mathrm{II}}$ complex $\left[(\mathrm{bpy})\left(\mathrm{H}_{2} \mathrm{O}\right) \mathrm{Ru}^{\mathrm{II}}(\mathrm{tpy}-\mathrm{DBF}-\mathrm{tpy}) \mathrm{Ru}^{\mathrm{II}}\left(\mathrm{OH}_{2}\right)(\mathrm{bpy})\right]^{4+}$, 
shown in Figure 6. Recent experiments ${ }^{45}$ have shown that the above complex undergoes reversible redox reactions to reach the stable oxidation state of $\left[(\mathrm{O}) \mathrm{Ru}^{\mathrm{IV}} \mathrm{Ru}^{\mathrm{IV}}(\mathrm{O})\right]^{4+}$ (inert ligands and linker have been omitted for clarity); further oxidation shows some evidence of water oxidation catalysis, but at present the experimental performance of this catalyst is uncertain.

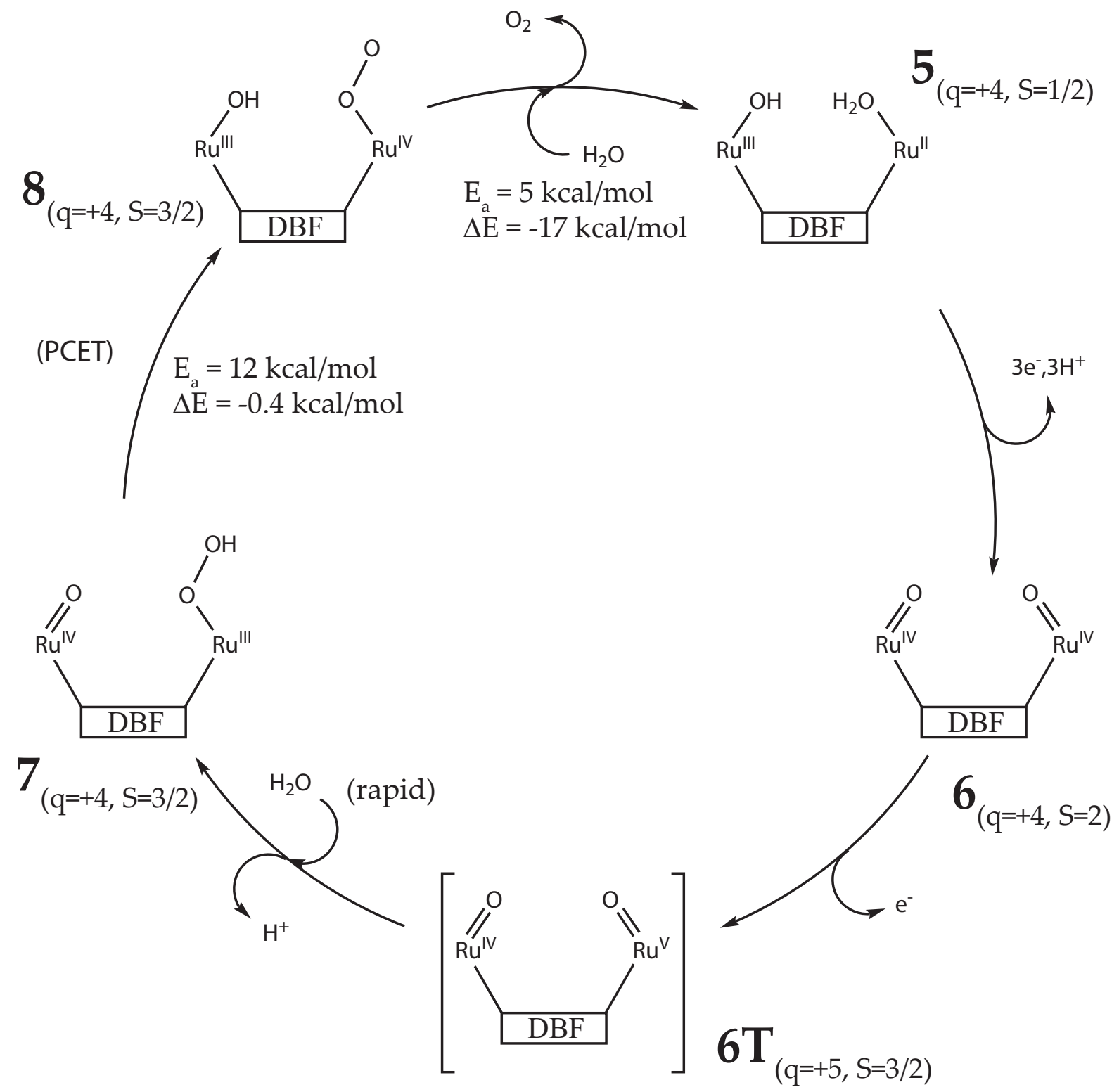

Figure 7: Proposed catalytic mechanism for the DBF-bridged two-center catalyst. Lowest-energy spin states are shown. 


\section{Mechanism}

In a previous account, ${ }^{45}$ we probed the possibility for a DC mechanism in the DBF-bridged twocenter complex. We found a large steric and electrostatic barrier ( $>50 \mathrm{kcal} / \mathrm{mol})$ against bringing the two subunits close together, and concluded that direct coupling was unlikely. Here, we focus instead on the viability of the AB picture for this two-center system. Our results are summarized in Figure 7, and involve intermediates highly similiar to those of the single-center mechanism. The computations involved consist mainly of geometry optimizations ${ }^{1}$; redox potential calculations were omitted due to the lack of detailed experimental redox data, and explicit solvent sampling was omitted due to the prohibitive computational cost of electronic structure calculations on this much larger system.

The initial state is the singly oxidized species $\left[(\mathrm{HO}) \mathrm{Ru}^{\mathrm{III}} \mathrm{Ru}^{\mathrm{II}}\left(\mathrm{OH}_{2}\right)\right]^{4+}(\mathbf{5})$. Three protoncoupled redox events give rise to the $\left[(\mathrm{O}) \mathrm{Ru}^{\mathrm{IV}} \mathrm{Ru}^{\mathrm{IV}}(\mathrm{O})\right]^{4+}$ state $(6)$, containing two ruthenium oxo groups. A fourth redox event yields the high-energy $\mathrm{Ru}^{\mathrm{V}}$-containing intermediate $\left[(\mathrm{O}) \mathrm{Ru}^{\mathrm{IV}} \mathrm{Ru}^{\mathrm{V}}(\mathrm{O})\right]^{5+}$ (6T), which undergoes nucleophilic attack by water and deprotonates to give $\left[(\mathrm{O}) \mathrm{Ru}^{\mathrm{IV}} \mathrm{Ru}^{\mathrm{III}}(\mathrm{OOH})\right]^{4+}$ (7). There is a marked similarity between this transformation and the $\mathrm{O}-\mathrm{O}$ bond forming step in the single-center case $(\mathbf{2} \rightarrow[\mathbf{2 T}] \rightarrow \mathbf{3})$. The $\mathrm{Ru}^{\mathrm{III}}(\mathrm{OOH})$ group in $\mathbf{7}$ is deprotonated via an intramolecular PCET event; this results in the peroxo species $\left[(\mathrm{HO}) \mathrm{Ru}^{\mathrm{III}} \mathrm{Ru}^{\mathrm{IV}}(\mathrm{OO})\right]^{4+}(\mathbf{8})$. The $\mathrm{Ru}^{\mathrm{IV}}(\mathrm{OO})$ peroxo is replaced by water in a substitution reaction to yield $\mathbf{5}$, releasing dioxygen and completing the catalytic cycle. Here we observe a similarity between this step and the turnover step in the single-center case $(\mathbf{4} \rightarrow \mathbf{0})$.

\section{$\mathrm{O}-\mathrm{O}$ bond formation}

We found that no $\mathrm{Ru}^{\mathrm{IV}}(\mathrm{O})-\mathrm{OH}_{2}$ bond can be formed at the $\mathbf{6}$ state despite an exhaustive search of bonding possibilities; this is not surprising considering the single-center catalyst 2 cannot

\footnotetext{
${ }^{1}$ There is experimental evidence for weak electronic coupling between the two $\mathrm{Ru}\left(\mathrm{OH}_{2}\right)$ subunits, which is plausible considering the long distance between the two metal centers. Our computational results also support this conclusion; the high-spin configuration and the low-spin broken symmetry (BS) configuration are isoenergetic as long as the number of unpaired electrons in each subunit is kept consistent. This allowed us to simulate the whole complex in a high-spin state instead of the much harder to converge BS state.
} 

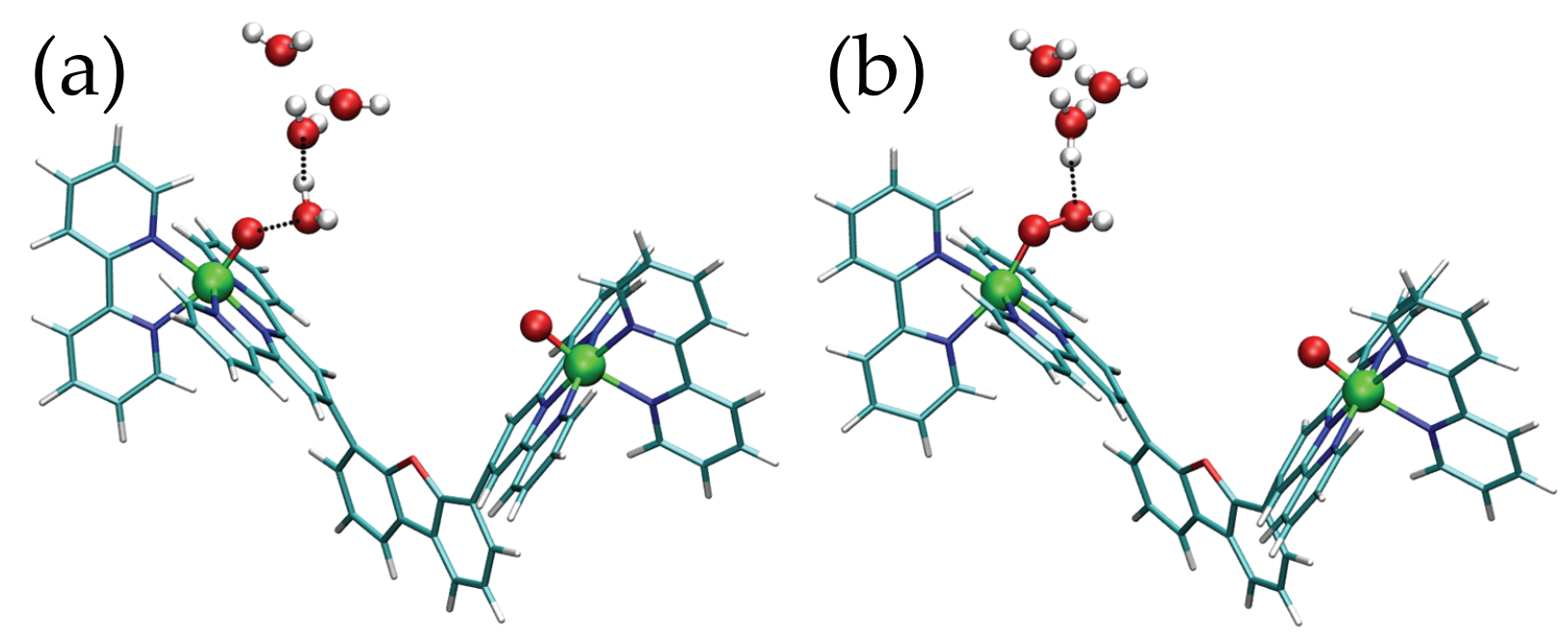

Figure 8: Initial (6T, left) and final (7, right) configurations for the $\mathrm{O}-\mathrm{O}$ bonding step. The $\mathrm{Ru}^{\mathrm{V}}$ side (left side of the molecule) is probed with water molecules. Key hydrogen bonds are indicated with dotted lines.

undergo $\mathrm{O}-\mathrm{O}$ bonding at the same oxidation state. Thus, we investigated the $\mathrm{O}-\mathrm{O}$ bonding chemistry of the $\mathrm{Ru}^{\mathrm{V}}$-containing intermediate $\mathbf{6 T}$, analogous to $2 \mathbf{T}$. Conventional DFT predicts that electrons are equally delocalized across this symmetric mixed-valence species in a formal $\left[(\mathrm{O}) \mathrm{Ru}^{4.5} \mathrm{Ru}^{4.5}(\mathrm{O})\right]^{5+}$ oxidation state, in which $\mathrm{Ru}^{\mathrm{V}}$ is absent and reactivity is decreased. Given the weak electronic coupling between the metal centers, this result is clearly unphysical, and likely a manifestation of the electron self-repulsion present in DFT. ${ }^{60,81}$ Thus, constrained DFT ${ }^{59}$ was used to obtain the proper electronic state of $\left[(\mathrm{O}) \mathrm{Ru}^{\mathrm{IV}} \mathrm{Ru}^{\mathrm{V}}(\mathrm{O})\right]^{5+}$. The molecule was partitioned into three regions - the two subunits plus the linker - for constrained DFT; the constraint regions were chosen to keep the cDFT potential from disrupting extended $\pi$-systems.

We found that the $\mathrm{Ru}^{\mathrm{V}}(\mathrm{O})$ oxo group in $\mathbf{6} \mathbf{T}$ undergoes nucleophilic attack by a water molecule, accompanied by concerted PT to solvent water molecules to form 7 . The reaction is spontaneous; i.e. no energy barrier is observed, similar to what we found for the reaction $(\mathbf{2 T} \rightarrow \mathbf{3})$ in the singlecenter case. This conclusion is based on the following results: first, the system $\left[(\mathrm{O}) \mathrm{Ru}^{\mathrm{IV}} \mathrm{Ru}^{\mathrm{V}}(\mathrm{O})\right.$ $\left.\mathrm{OH}_{2}\right]^{5+}\left(\mathbf{6 T}+\mathrm{H}_{2} \mathrm{O}\right)$ has an energy minimum in the $\mathrm{Ru}(\mathrm{O})-\mathrm{OH}_{2}$ coordinate where the distance is approximately $2.0 \AA$ (Figure 8a). Three additional water molecules are manually placed nearby as hydrogen-bond acceptors. Geometry optimization starting from this configuration leads to the 
product configuration, $\left[(\mathrm{O}) \mathrm{Ru}^{\mathrm{IV}} \mathrm{Ru}^{\mathrm{III}}(\mathrm{OOH})\right]^{4+}(7)$, where an $\mathrm{O}-\mathrm{O}$ bond has formed and a proton has been transferred to an acceptor water molecule (Figure 8b). From the Mulliken charge distribution of the product configuration, and judging by the essential nature of PT in this process, it is clear that the $\mathrm{O}-\mathrm{O}$ bonding mechanism follows the same $\mathrm{AB}$ picture as in the single-center case.

\section{Deprotonation of the hydroperoxo group and dioxygen release}

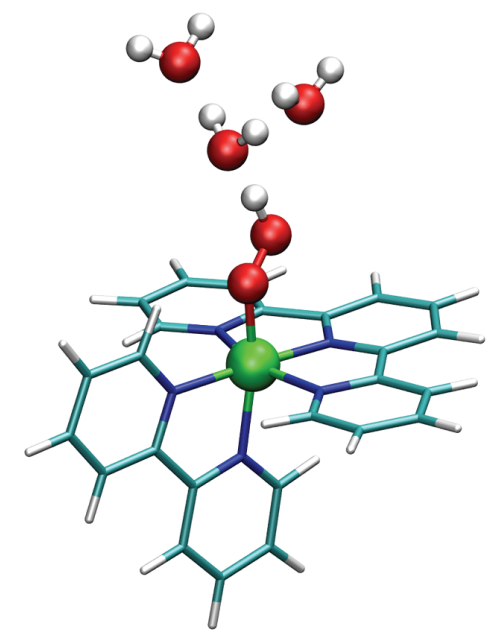

Figure 9: Attempted deprotonation of the hydroperoxo group in the monomeric analogue, $\left[\mathrm{Ru}^{\mathrm{III}}(\mathrm{tpy})(\mathrm{bpy})(\mathrm{OOH})\right]^{2+}$.

We investigated the deprotonation of the $\mathrm{Ru}^{\mathrm{III}}(\mathrm{OOH})$ group in 7 by first examining unassisted PT from the monomeric analogue, $[\mathrm{Ru}(\mathrm{tpy})(\mathrm{bpy})(\mathrm{OOH})]^{2+}$, to three solvent water molecules (Figure 9). Using constrained geometry optimizations, we lengthened the $\mathrm{Ru}(\mathrm{OO}-\mathrm{H})$ bond from $1.068 \AA$ to $1.52 \AA$. The $\mathrm{H}-\mathrm{OH}_{2}$ distance from the terminal proton to the nearest water molecule concurrently decreased from $1.43 \AA$ to $1.06 \AA$, giving a small indication of PT. However, we found that the energy steadily increased to a net penalty of $4.84 \mathrm{kcal} / \mathrm{mol}$, and no stable PT configuration was found. We inferred from this result that the $\mathrm{Ru}^{\mathrm{III}}(\mathrm{OOH})$ group in 7 will not spontaneously lose a proton to solvent.

We found that deprotonation can occur via an alternative pathway involving the second $\mathrm{Ru}$ center, characterized by a combined intramolecular PCET process. To investigate this pathway, we 
fully optimized the geometry of $\left[(\mathrm{O}) \mathrm{Ru}^{\mathrm{IV}} \mathrm{Ru}^{\mathrm{III}}(\mathrm{OOH})\right]^{4+}$, then initiated ET using CDFT to create the $\left[(\mathrm{O}) \mathrm{Ru}^{\mathrm{III}} \mathrm{Ru}^{\mathrm{IV}}(\mathrm{OOH})\right]^{4+}$ electronic state. Subsequent relaxation of the geometry leads to the $\left[(\mathrm{HO}) \mathrm{Ru}^{\mathrm{III}} \mathrm{Ru}^{\mathrm{IV}}(\mathrm{OO})\right]^{4+}$, provided that a water bridge is included to facilitate PT. Figure 10 (top) displays the reactant and product structures of this reaction.
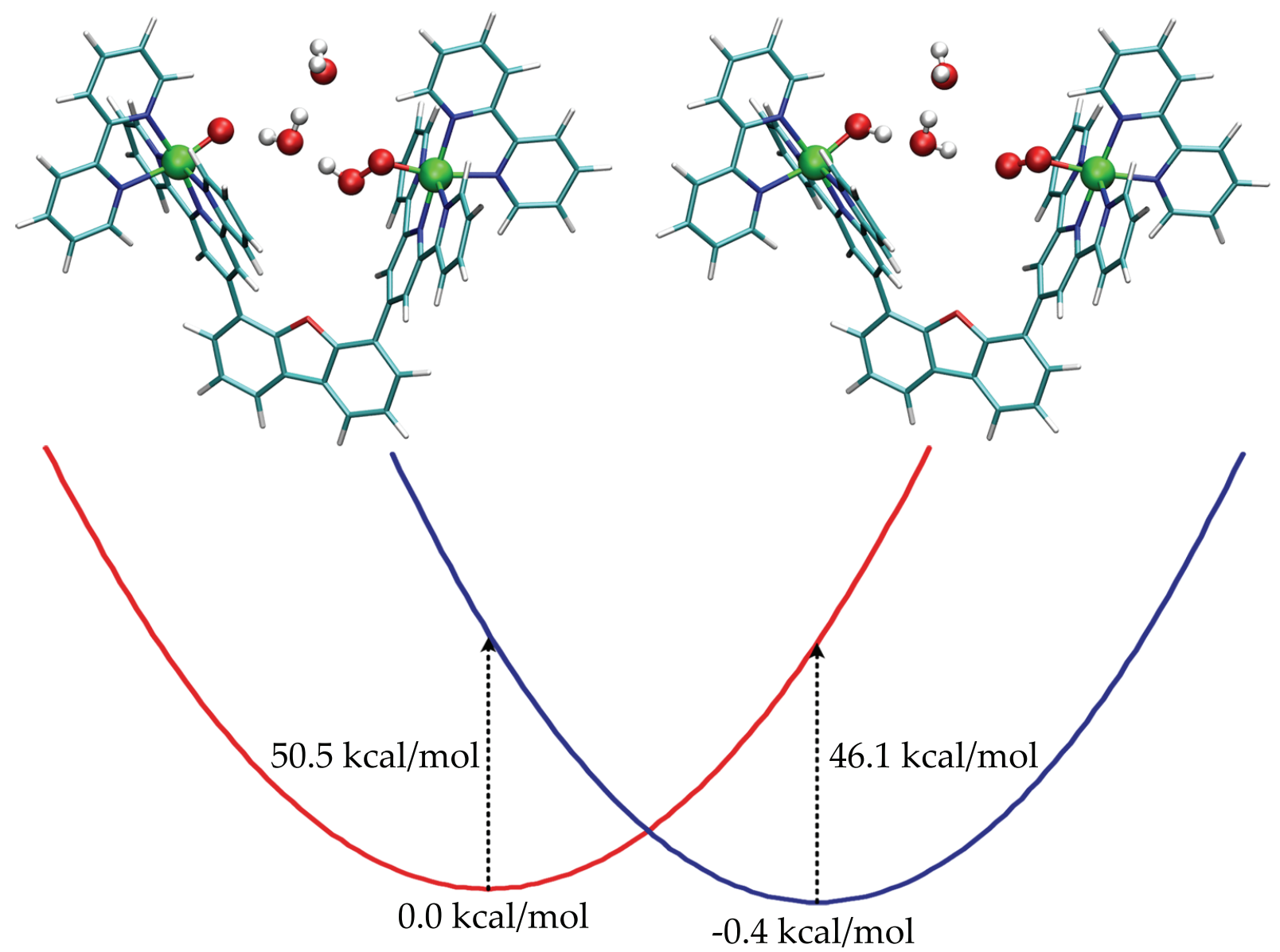

Figure 10: Marcus energy diagram showing the reactant $\left[(\mathrm{O}) \mathrm{Ru}^{\mathrm{IV}} \mathrm{Ru}^{\mathrm{III}}(\mathrm{OOH})\right]^{4+}$ and product $\left[(\mathrm{HO}) \mathrm{Ru}^{\mathrm{III}} \mathrm{Ru}^{\mathrm{IV}}(\mathrm{OO})\right]^{4+}$ configurations in the final PCET step.

We did not investigate the sequential pathways by which PT and ET may occur. However, if a concerted pathway is assumed, which is reasonable because it has the lowest activation energy, ${ }^{82,83}$ we could estimate the barrier height using the driving force $\Delta \mathrm{G}$ and reorganization energies $\lambda^{81}$ using the Marcus theory formula $E_{a}=(\Delta G+\lambda)^{2} / 4 \lambda$. Figure 10 (bottom) shows the energetic relationships using a single combined PT and ET coordinate. We found a small driving force 
( $\Delta G=-0.4 \mathrm{kcal} / \mathrm{mol})$. Our calculated values of $\lambda$ are slightly different for reactant and product; $\lambda_{R}=50.9 \mathrm{kcal} / \mathrm{mol}$ and $\lambda_{P}=46.1 \mathrm{kcal} / \mathrm{mol}$. We chose to use the average of the two $\lambda$ values which yields an activation energy of $11.9 \mathrm{kcal} / \mathrm{mol}$.

In the single-center case, we note that the deprotonation of $\mathbf{3}$ was accomplished by a fourth redox event. In the case of $\mathbf{7}$, the second $\mathrm{Ru}$ center effectively acts as an oxidant in allowing the final deprotonation to occur; $\mathrm{Ru}^{\mathrm{III}}(\mathrm{OOH})$ is oxidized to $\mathrm{Ru}^{\mathrm{IV}}(\mathrm{OO})$, and $\mathrm{Ru}^{\mathrm{IV}}(\mathrm{O})$ is reduced to $\mathrm{Ru}^{\mathrm{III}}(\mathrm{OH})$. The small driving force and relatively large barrier against PT here suggests that the final deprotonation step in the two-center catalyst may be very slow.

The release of $\mathrm{O}_{2}$ from the $\mathrm{Ru}^{\mathrm{IV}}(\mathrm{OO})$ group in $\mathbf{8}$ is accomplished by a ligand substitution with water, similar to the single-center case. The overall reaction $(\mathbf{8} \rightarrow \mathbf{5})$ is downhill by $17.8 \mathrm{kcal} / \mathrm{mol}$. We found the transition state with a barrier of $5.9 \mathrm{kcal} / \mathrm{mol}$; this value is consistent with the barrier for dioxygen displacement in the reaction $(\mathbf{4} \rightarrow \mathbf{0})$.

\section{Discussion and Conclusions}

The design of efficient and robust water oxidation catalysts has much to benefit from an improved understanding of the mechanism. ${ }^{84}$ Until recently, there has been an abundance of cofacial twocenter Ru systems in attempts to pursue the rational design of water oxidation catalysts, which are largely inspired by the blue dimer. While many of these systems had been designed with the DC picture in mind, ${ }^{29,30}$ there is also evidence that catalysis proceeds via the $\mathrm{AB}$ picture at one metal center, with the other metal center playing an assisting role. ${ }^{37,49}$ These two-center systems are capable of water oxidation, but syntheses of these catalysts are highly difficult, and a strategy for optimizing catalyst figures of merit (overpotentials, turnover numbers, and operating conditions) remains elusive.

The recent discovery of single-center catalysts ${ }^{25,26,31}$ introduced a new perspective on catalytic water oxidation. The single-center catalysts strengthen the possibility of an $\mathrm{AB}$ picture where a water nucleophile attacks a single metal oxo group to form the $\mathrm{O}-\mathrm{O}$ bond. Following formation 
of the $\mathrm{O}-\mathrm{O}$ bond, the water nucleophile loses a proton to the solvent, lifting the requirement for a second metal center to assist in deprotonation.

In this work, we have presented a complete picture of the water oxidation mechanism in the single-center catalyst $\left[\mathrm{Ru}(\mathrm{tpy})(\mathrm{bpm})\left(\mathrm{OH}_{2}\right)\right]^{2+}$. Our calculations clearly support the AB picture as a viable pathway for $\mathrm{O}-\mathrm{O}$ bond formation, providing important validation for the mechanistic proposal put forth in Ref. 25. The oxidation of $\mathrm{Ru}^{\mathrm{IV}}(\mathrm{O})$ to $\mathrm{Ru}^{\mathrm{V}}(\mathrm{O})$ is energetically demanding, but the subsequent nucleophilic attack of water on $\mathrm{Ru}^{\mathrm{V}}(\mathrm{O})$ occurs nearly spontaneously, forming an $\mathrm{O}-\mathrm{O}$ bond without going through a large kinetic barrier. The steps following $\mathrm{O}-\mathrm{O}$ bonding proceed spontaneously to release molecular oxygen and complete the catalytic cycle.

We have also found a water oxidation mechanism that proceeds via the AB picture in the twocenter DBF-bridged catalyst, $\left[(\right.$ bpy $)\left(\mathrm{H}_{2} \mathrm{O}\right) \mathrm{Ru}^{\mathrm{II}}\left(\text { tpy-DBF-tpy) } \mathrm{Ru}{ }^{\mathrm{II}}\left(\mathrm{OH}_{2}\right)(\mathrm{bpy})\right]^{4+}$. There exists a significant similarity between the $\mathrm{O}-\mathrm{O}$ bonding steps of the two-center catalyst and the one-center catalyst. For both catalysts, $\mathrm{O}-\mathrm{O}$ bonding occurs via an acid-base reaction initiated by oxidation of one $\mathrm{Ru}$ center to $\mathrm{Ru}^{\mathrm{V}}$, followed by nucleophilic attack of water and PT to the solvent. We found that the second metal center does not play an assistive role in the $\mathrm{O}-\mathrm{O}$ bonding step, as has been proposed in DFT studies of other two-center catalysts; ${ }^{40,43}$ however, it assists in deprotonation of the hydroperoxo group after $\mathrm{O}-\mathrm{O}$ bonding is complete via a PCET mechanism.

There are several obvious directions for extending this work. In terms of theoretical methods, in the future we would like to improve the redox potential estimates using more advanced solvation models; the determination of solvation energies using explicit solvent free energy perturbation (FEP) is a promising, if costly, option. ${ }^{85}$ Our methodology for investigating $\mathrm{O}-\mathrm{O}$ bonding could be further refined; we used an MM simulation to sample the solvent configuration space, but a QM/MM simulation may be more appropriate. Furthermore, one may obtain more accurate estimates of reaction probabilities and discover alternative pathways by using a larger number of snapshots. The theoretical exploration of alternative reactions (e.g. catalyst poisoning and degradation), especially at the highly reactive $\mathrm{Ru}^{\mathrm{V}}$ oxidation state, may also prove useful in identifying factors that limit catalyst turnover. Notably, we have shown that the inclusion of explicit solvent is 
indispensible when investigating key steps of the catalytic cycle, and we hope that future theoretical studies will take this important consideration into account.

On the more experimental side, we note that while the AB picture is by no means universal, our results suggest that the mechanism is at least transferable across several systems. Thus, an obvious future direction entails applying the same $\mathrm{AB}$ mechanism to other catalyst families, including the array of Ru-center catalysts discovered in Thummel's group ${ }^{27}$ and the Ir-center catalysts discovered in Bernhard's group. ${ }^{26}$ One would also like to confirm the viability of the AB mechanism in more well-known systems such as the blue dimer and (ultimately) the OEC. The mechanism of these catalysts (AB versus DC) is likely determined by the ability of the highest metal oxidation state to act as a Lewis acid. In the systems studied here this requires a transient $\mathrm{Ru}^{\mathrm{V}}$ center, whereas many of the aforementioned catalysts top out at $\mathrm{Ru}^{\mathrm{IV}}$. It is yet to be seen if any of the $\mathrm{Ru}^{\mathrm{IV}}$ ions are suitably reactive for the $\mathrm{AB}$ mechanism.

Our work provides key support for the acid-base mechanism of water oxidation catalysis and encourages new directions of research for the catalyst development community. Perhaps most importantly, our verification of the AB picture strongly encourages further design of single-center catalysts, in contrast to the synthetically much more difficult two-center paradigm. We offer our suggestion that the difficulty in achieving $\mathrm{O}-\mathrm{O}$ bonding in the $\mathrm{AB}$ picture can be mitigated by

fine-tuning ligand fields to lower the redox potential of the $\mathrm{Ru}^{\mathrm{IV}} / \mathrm{Ru}^{\mathrm{V}}$ couple, pre-orienting the reactant water molecule in the first solvation shell, or alternatively by employing metals (such as cobalt) that might be slightly more reactive in their IV oxidation state.

\section{Acknowledgement}

This work was funded by ENI S.p.A. as part of the Solar Frontiers Research Program. Q.W. acknowledges support from the U.S. Department of Energy, Office of Basic Energy Sciences, under Contract No. DE-AC02-98CH10886. T. V. gratefully acknowledges a fellowship from the David \& Lucille Packard Foundation. We thank Yogesh Surendranath for insightful discussion. 


\section{Supporting Information Available}

Supporting Information Available: Complete Refs. $64 \&$ 65, experimental and calculated redox data for reference $\mathrm{Ru}$ complexes, and linear fit to experimental redox data. This material is available free of charge via the Internet at http://pubs.acs.org.

\section{References}

(1) Lewis, N. S.; Nocera, D. G. P. Natl. Acad. Sci. USA 2006, 103, 15729-15735.

(2) Muckerman, J. T.; Polyansky, D. E.; Wada, T.; Tanaka, K.; Fujita, E. Inorg. Chem. 2008, 47, $1787-1802$.

(3) Manchanda, R.; Brudvig, G. W.; Crabtree, R. H. Coordin. Chem. Rev. 1995, 144, 1-38.

(4) Yachandra, V. K.; Sauer, K.; Klein, M. P. Chem. Rev. 1996, 96, 2927-2950.

(5) Ruttinger, W.; Dismukes, G. C. Chem. Rev. 1997, 97, 1-24.

(6) Ferreira, K. N.; Iverson, T. M.; Maghlaoui, K.; Barber, J.; Iwata, S. Science 2004, 303, 1831 1838.

(7) Pushkar, Y. L.; Yano, J.; Sauer, K.; Boussac, A.; Yachandra, V. K. P. Natl. Acad. Sci. USA 2008, 105, 1879-1884.

(8) Yano, J.; Yachandra, V. K. Inorg. Chem. 2008, 47, 1711-1726.

(9) Barber, J. Inorg. Chem. 2008, 47, 1700-1710.

(10) Wincencjusz, H.; vanGorkom, H. J.; Yocum, C. F. Biochem. 1997, 36, 3663-3670.

(11) Ahrling, K. A.; Peterson, S.; Styring, S. Biochem. 1997, 36, 13148-13152.

(12) Iuzzolino, L.; Dittmer, J.; Dorner, W.; Meyer-Klaucke, W.; Dau, H. Biochem. 1998, 37, 17112-17119. 
(13) Vrettos, J. S.; Limburg, J.; Brudvig, G. W. BBA-Bioenergetics 2001, 1503, 229-245.

(14) Robblee, J. H.; Cinco, R. M.; Yachandra, V. K. BBA-Bioenergetics 2001, 1503, 7-23.

(15) Messinger, J.; Robblee, J. H.; Bergmann, U.; Fernandez, C.; Glatzel, P.; Visser, H.; Cinco, R. M.; McFarlane, K. L.; Bellacchio, E.; Pizarro, S. A.; Cramer, S. P.; Sauer, K.; Klein, M. P.; Yachandra, V. K. J. Am. Chem. Soc. 2001, 123, 7804-7820.

(16) Britt, R. D.; Campbell, K. A.; Peloquin, J. M.; Gilchrist, M. L.; Aznar, C. P.; Dicus, M. M.; Robblee, J.; Messinger, J. BBA-Bioenergetics 2004, 1655, 158-171.

(17) McEvoy, J. P.; Brudvig, G. W. Phys. Chem. Chem. Phys. 2004, 6, 4754-4763.

(18) Haumann, M.; Muller, C.; Liebisch, P.; Iuzzolino, L.; Dittmer, J.; Grabolle, M.; Neisius, T.; Meyer-Klaucke, W.; Dau, H. Biochem. 2005, 44, 1894-1908.

(19) Yano, J.; Kern, J.; Irrgang, K. D.; Latimer, M. J.; Bergmann, U.; Glatzel, P.; Pushkar, Y.; Biesiadka, J.; Loll, B.; Sauer, K.; Messinger, J.; Zouni, A.; Yachandra, V. K. P. Natl. Acad. Sci. USA 2005, 102, 12047-12052.

(20) Nishiyama, Y.; Allakhverdiev, S. I.; Murata, N. BBA-Bioenergetics 2006, 1757, 742-749.

(21) McEvoy, J. P.; Brudvig, G. W. Chem. Rev. 2006, 106, 4455-4483.

(22) Sproviero, E. M.; Gascon, J. A.; McEvoy, J. P.; Brudvig, G. W.; Batista, V. S. J. Am. Chem. Soc. 2008, 130, 3428-3442.

(23) Siegbahn, P. E. M. Inorg. Chem. 2008, 47, 1779-1786.

(24) Rossmeisl, J.; Dimitrievski, K.; Siegbahn, P.; Norskov, J. K. J. Phys. Chem. C 2007, 111, $18821-18823$.

(25) Concepcion, J. J.; Jurss, J. W.; Templeton, J. L.; Meyer, T. J. J. Am. Chem. Soc. 2008, 130, $16462-+$. 
(26) McDaniel, N. D.; Coughlin, F. J.; Tinker, L. L.; Bernhard, S. J. Am. Chem. Soc. 2008, 130, $210-217$.

(27) Tseng, H. W.; Zong, R.; Muckerman, J. T.; Thummel, R. Inorg. Chem. 2008, 47, 1176311773.

(28) Gilbert, J. A.; Eggleston, D. S.; Murphy, W. R.; Geselowitz, D. A.; Gersten, S. W.; Hodgson, D. J.; Meyer, T. J. J. Am. Chem. Soc. 1985, 107, 3855-3864.

(29) Wada, T.; Tsuge, K.; Tanaka, K. Inorg. Chem. 2001, 40, 329-337.

(30) Sens, C.; Romero, I.; Rodriguez, M.; Llobet, A.; Parella, T.; Benet-Buchholz, J. J. Am. Chem. Soc. 2004, 126, 7798-7799.

(31) Zong, R.; Thummel, R. P. J. Am. Chem. Soc. 2005, 127, 12802-12803.

(32) Brimblecombe, R.; Swiegers, G. F.; Dismukes, G. C.; Spiccia, L. Angew. Chem. Int. Ed. 2008, 47, 7335-7338.

(33) Sartorel, A.; Carraro, M.; Scorrano, G.; Zorzi, R. D.; Geremia, S.; McDaniel, N. D.; Bernhard, S.; Bonchio, M. J. Am. Chem. Soc. 2008, 130, 5006-+.

(34) Kanan, M. W.; Nocera, D. G. Science 2008, 321, 1072-1075.

(35) Fujishima, A.; Honda, K. Nature 1972, 238, 37-38.

(36) Zou, Z. G.; Ye, J. H.; Sayama, K.; Arakawa, H. Nature 2001, 414, 625-627.

(37) Liu, F.; Concepcion, J. J.; Jurss, J. W.; Cardolaccia, T.; Templeton, J. L.; Meyer, T. J. Inorg. Chem. 2008, 47, 1727-1752.

(38) Bartolotti, L. J.; Pedersen, L. G.; Meyer, T. J. Int. J. Quantum Chem. 2001, 83, 143-149.

(39) Yang, X. F.; Baik, M. H. J. Am. Chem. Soc. 2004, 126, 13222-13223.

(40) Yang, X.; Baik, M. H. J. Am. Chem. Soc. 2006, 128, 7476-7485. 
(41) Batista, E. R.; Martin, R. L. J. Am. Chem. Soc. 2007, 129, 7224-+.

(42) Valdes, A.; Kroes, G. J. J. Chem. Phys. 2009, 130, 114701.

(43) Yang, X. F.; Baik, M. H. J. Am. Chem. Soc. 2008, 130, 16231-16240.

(44) Bozoglian, F.; Romain, S.; Ertem, M. Z.; Todorova, T. K.; Sens, C.; Mola, J.; Rodriguez, M.; Romero, I.; Benet-Buchholz, J.; Fontrodona, X.; Cramer, C. J.; Gagliardi, L.; Llobet, A. J. Am. Chem. Soc. 2009, 131, 15176-15187.

(45) Betley, T. A.; Wu, Q.; Voorhis, T. V.; Nocera, D. G. Inorg. Chem. 2008, 47, 1849-1861.

(46) Romain, S.; Bozoglian, F.; Sala, X.; Llobet, A. J. Am. Chem. Soc. 2009, 131, 2768-+.

(47) Peloquin, J. M.; Campbell, K. A.; Randall, D. W.; Evanchik, M. A.; Pecoraro, V. L.; Armstrong, W. H.; Britt, R. D. J. Am. Chem. Soc. 2000, 122, 10926-10942.

(48) Hurst, J. K.; Zhou, J. Z.; Lei, Y. B. Inorg. Chem. 1992, 31, 1010-1017.

(49) Yamada, H.; Siems, W. F.; Koike, T.; Hurst, J. K. J. Am. Chem. Soc. 2004, 126, 9786-9795.

(50) Concepcion, J. J.; Jurss, J. W.; Brennaman, M. K.; Hoertz, P. G.; Patrocinio, A. O. T.; Iha, N. Y. M.; Templeton, J. L.; Meyer, T. J. Acc. Chem. Res. 2009, 42, 1954-1965.

(51) Concepcion, J. J.; Tsai, M. K.; Muckerman, J. T.; Meyer, T. J. J. Am. Chem. Soc. 2010, 132, 1545-1557.

(52) Yoshida, M.; Masaoka, S.; Sakai, K. Chem. Lett. 2009, 38, 702-703.

(53) Concepcion, J. J.; Jurss, J. W.; Hoertz, P. G.; Meyer, T. J. Angew. Chem. Int. Ed. 2009, 48, 9473-9476.

(54) Duan, L. L.; Xu, Y. H.; Zhang, P.; Wang, M.; Sun, L. C. Inorg. Chem. 2010, 49, 209-215.

(55) Wasylenko, D. J.; Ganesamoorthy, C.; Koivisto, B. D.; Henderson, M. A.; Berlinguette, C. P. Inorg. Chem. 2010, 49, 2202-2209. 
(56) Becke, A. D. J. Chem. Phys. 1993, 98, 5648-5652.

(57) Hariharan, P. C.; Pople, J. A. Theor. Chim. Acta 1973, 28, 213-222.

(58) Hay, P. J.; Wadt, W. R. J. Chem. Phys. 1985, 82, 299-310.

(59) Wu, Q.; Voorhis, T. V. Phys. Rev. A 2005, 72, 024502.

(60) Perdew, J. P.; Zunger, A. Phys. Rev. B 1981, 23, 5048-5079.

(61) Schafer, A.; Huber, C.; Ahlrichs, R. J. Chem. Phys. 1994, 100, 5829-5835.

(62) Andrae, D.; Haussermann, U.; Dolg, M.; Stoll, H.; Preuss, H. Theor. Chim. Acta 1990, 77, $123-141$.

(63) Barone, V.; Cossi, M. J. Phys. Chem. A 1998, 102, 1995-2001.

(64) Frisch, M. J. et al. Gaussian 03, Revision C.02, Gaussian, Inc., Wallingford, CT, 2004.

(65) Shao, Y. et al. Phys. Chem. Chem. Phys. 2006, 8, 3172-3191.

(66) der Spoel, D. V.; Lindahl, E.; Hess, B.; Groenhof, G.; Mark, A. E.; Berendsen, H. J. C. J. Comput. Chem. 2005, 26, 1701-1718.

(67) Winget, P.; Cramer, C. J.; Truhlar, D. G. Theor. Chem. Acc. 2004, 112, 217-227.

(68) Baik, M. H.; Friesner, R. A. J. Phys. Chem. A 2002, 106, 7407-7412.

(69) Norskov, J. K.; Rossmeisl, J.; Logadottir, A.; Lindqvist, L.; Kitchin, J. R.; Bligaard, T.; Jonsson, H. J. Phys. Chem. B 2004, 108, 17886-17892.

(70) Mejias, J. A.; Hamad, S.; Lago, S. J. Phys. Chem. B 2001, 105, 9872-9878.

(71) Tissandier, M. D.; Cowen, K. A.; Feng, W. Y.; Gundlach, E.; Cohen, M. H.; Earhart, A. D.; Coe, J. V.; Tuttle, T. R. J. Phys. Chem. A 1998, 102, 7787-7794.

(72) Kelly, C. P.; Cramer, C. J.; Truhlar, D. G. J. Phys. Chem. B 2007, 111, 408-422. 
(73) Dovletoglou, A.; Adeyemi, S. A.; Meyer, T. J. Inorg. Chem. 1996, 35, 4120-4127.

(74) Masllorens, E.; Rodriguez, M.; Romero, I.; Roglans, A.; Parella, T.; Benet-Buchholz, J.; Poyatos, M.; Llobet, A. J. Am. Chem. Soc. 2006, 128, 5306-5307.

(75) Jorgensen, W. L.; Tiradorives, J. J. Am. Chem. Soc. 1988, 110, 1657-1666.

(76) Berendsen, H. J. C.; Grigera, J. R.; Straatsma, T. P. J. Phys. Chem 1987, 91, 6269-6271.

(77) Nose, S. J. Chem. Phys. 1984, 81, 511-519.

(78) Berendsen, H. J. C.; Postma, J. P. M.; Vangunsteren, W. F.; Dinola, A.; Haak, J. R. J. Chem. Phys. 1984, 81, 3684-3690.

(79) Cape, J. L.; Hurst, J. K. J. Am. Chem. Soc. 2008, 130, 827-829.

(80) Cape, J. L.; Siems, W. F.; Hurst, J. K. Inorg. Chem. 2009, 48, 8729-8735.

(81) Wu, Q.; Voorhis, T. V. J. Phys. Chem. A 2006, 110, 9212-9218.

(82) Cukier, R. I.; Nocera, D. G. Annu. Rev. Phys. Chem. 1998, 49, 337-369.

(83) Soudackov, A.; Hammes-Schiffer, S. J. Am. Chem. Soc. 1999, 121, 10598-10607.

(84) Meyer, T. J. Nature 2008, 451, 778-779.

(85) Marten, B.; Kim, K.; Cortis, C.; Friesner, R. A.; Murphy, R. B.; Ringnalda, M. N.; Sitkoff, D.; Honig, B. J. Phys. Chem. 1996, 100, 11775-11788. 


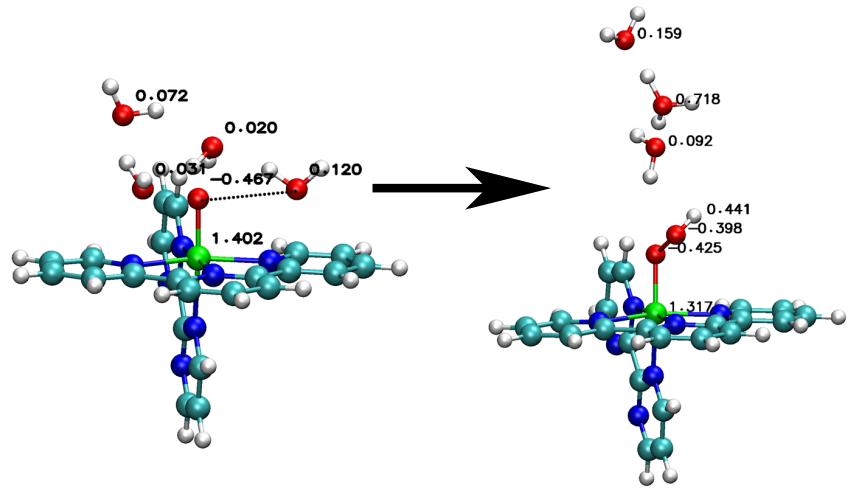

Starting and ending points of a geometry optimization starting at $\mathrm{Ru}{ }^{\mathrm{V}}(\mathrm{O})$ and ending at $\mathrm{Ru}^{\mathrm{III}}(\mathrm{OOH}) . \mathrm{O}-\mathrm{O}$ bonding occurs via the acid-base mechanism; the reacting oxygen atoms are connected by a dotted line. Analysis of the Mulliken charges (labeled) shows concomitant proton transfer to the solvent water molecules.

This material is available free of charge via the Internet at http://pubs . acs . org/. 